\title{
Numerical simulation of resistance sintering of titanium by a porous continuum approach
}

\author{
Cannella, E.; Martins, P.A.F.; Nielsen, C. V.
}

Published in:

Journal of Manufacturing Science and Engineering

Link to article, DOI:

$10.1115 / 1.4052208$

Publication date:

2022

Document Version

Peer reviewed version

Link back to DTU Orbit

Citation $(A P A)$ :

Cannella, E., Martins, P. A. F., \& Nielsen, C. V. (2022). Numerical simulation of resistance sintering of titanium by a porous continuum approach. Journal of Manufacturing Science and Engineering, 144(4), [041005]. https://doi.org/10.1115/1.4052208

\section{General rights}

Copyright and moral rights for the publications made accessible in the public portal are retained by the authors and/or other copyright owners and it is a condition of accessing publications that users recognise and abide by the legal requirements associated with these rights.

- Users may download and print one copy of any publication from the public portal for the purpose of private study or research.

- You may not further distribute the material or use it for any profit-making activity or commercial gain

- You may freely distribute the URL identifying the publication in the public portal 


\title{
Numerical simulation of resistance sintering of titanium by a porous continuum approach
}

\author{
E. Cannella ${ }^{1}$, P.A.F. Martins ${ }^{2}$, C.V. Nielsen ${ }^{1 *}$ \\ ${ }^{1}$ Technical University of Denmark, Kgs. Lyngby, Denmark. \\ ${ }^{2}$ IDMEC, Instituto Superior Técnico, Universidade de Lisboa, Portugal. \\ ${ }^{*}$ Corresponding author: cvni@mek.dtu.dk
}

\begin{abstract}
This paper presents a numerical model for the simulation of resistance sintering. It involves an electro-thermo-mechanical coupling, where each model is simulated as a continuum with the influence of porosities included through the distribution of relative density, i.e. the ratio of the apparent density to that of the corresponding fully dense bulk material. For the mechanical response, this involves a plasticity model based on a porous formulation. Other material data have to be supplied as a function of relative density and temperature, as for example the electrical resistivity. The numerical modeling is compared to experimentally resistance sintered titanium with good agreement in terms of pre-compaction and developed relative density and temperature during the sintering process.
\end{abstract}

Keywords: Resistance sintering; finite element method, porous model; coupled simulation

\section{Introduction}

In the field of powder metallurgy, sintering processes are applicable to manufacture near net-shape components by compaction and heating of metal powder [1]. Among the newest sintering approaches, resistance sintering has recently gained ground because of the advantageous reduction of time and high heating rate which can be achieved. This is possible by electro-thermo-mechanical effects, which improve the particle bonding and generate sintering in a fraction of a second [2]. Several sintering processes based on this approach can be found. They are generally divided into two main sub-groups [3]. The main differences are the process parameters, i.e. electrical current and processing time, and on the die materials, which can be either conductive or insulating. Resistance sintering generally employs a high electrical current and a short sintering time, while 
spark plasma sintering is characterized by lower electrical current and longer sintering times [4]. Resistance sintering makes use of electrically insulating dies to focus the heat generation to the sample only [5], while spark plasma sintering employs electrically conductive dies that are also heated.

A large number of different materials can be found in literature, as resistance sintering has been applied to gold [6], copper [7] and hard metals as tungsten carbide [8], chromium carbide [9], and titanium [10,11]. Recently, Leich et al. [12] and Cannella et al. [13] applied the process to sintering of an Nd-alloy for producing permanent magnets.

The interest in simulating the process is inspired by the knowledge of process parameters, such as temperature which is difficult to measure inside the sample and at high gradients and electrical currents. Direct temperature measurements are not possible by using conventional instruments, as thermocouples, when high electrical currents are flowing within the compacted powder. Furthermore, the resistance sintering process takes place in a closed die setup, making the use of infrared instruments as thermo cameras and pyrometers impossible. As a consequence, there is no literature dealing with direct temperature measurements in resistance sintering. Besides the estimation of process parameters, numerical simulations can assist process optimization by estimating the final density, which can be achieved at different combinations of compaction pressure, sintering time and electrical current. This method is beneficial especially when approaching a new material.

Few studies were found to investigate numerical simulations [14]. Two main approaches can be identified, i.e. particle-based and continuum-based. Maizza and Tassinari [15] have modelled the densification phenomena and temperature during capacitor discharge sintering by adopting a particle-based approach, which works on a microscopic scale. The particle size and chemical condition of the surfaces are crucial assumptions to be set before simulating. McWilliams et al. [16] investigated the generated thermal gradients by numerical simulations to optimize the spark plasma sintering process in terms of density. Zhang et al. [17] produced a molecular dynamic model to estimate the electrical resistivity of silver nanoparticles during low temperature sintering. Wei et al. [18] showed the dominant effect of the contact resistance in the temperature evolution by experimental-numerical data validation. Tiwari et al. [19] studied the electrical field and obtained temperature in spark plasma sintering by continuum modelling in Abaqus. Braginsky et al. [20] modeled the microstructural evolution and particle deformation during sintering. Garcia and Olevsky [21] followed the 
continuum-based theory to estimate the evolution of density during processing, and Allen and Walter [22] performed transient finite element modelling on a field assisted sintering technique (FAST) of aluminum oxide, by integrating the electrical, thermal and mechanical governing equations.

This paper focuses on the modelling of resistance sintering by means of a continuumbased approach. The material is considered on a macroscopic scale and average values are assumed for the properties of the simulated material for each element in the discretized domain. Densities and temperatures are estimated as a function of different process parameters; namely electrical current, sintering time and compacting pressure. Material properties are implemented as a function of temperatures and relative density. The approach has some similarities with electro-thermo-mechanical modeling of resistance welding [23,24], but now with the addition of a porous formulation. The developments are done in the in-house computer program i-form [25] based on the finite element flow formulation.

\section{Experimental setup and material properties}

\subsection{Experimental setup}

Figure 1 shows the experimental setup for resistance sintering of titanium discs by Cannella et al. $[11,26]$. The process takes place in a middle-frequency direct current (MFDC) resistance welding machine (Expert 170kVA with Harms \& Wende HWI 2000 control unit). The setup consists of a die made of aluminum oxide $\left(\mathrm{Al}_{2} \mathrm{O}_{3} 99.7 \%\right.$ purity) placed on a bottom punch. After placing the titanium powder inside the container, a second punch is placed above. The welding machine supplies the force for compaction and the electrical current for resistance heating and sintering. Force and current are measured by the load cell and Rogowski coil shown in Figure 1b. Titanium discs of diameter $\varnothing 10 \mathrm{~mm}$ and thickness $3 \mathrm{~mm}$ are sintered in this case (Figure 1c).

The density of sintered discs was estimated by measuring the weight of each sample with a precision balance and the volume by using 3D optical scanning (see further details in [11]). 


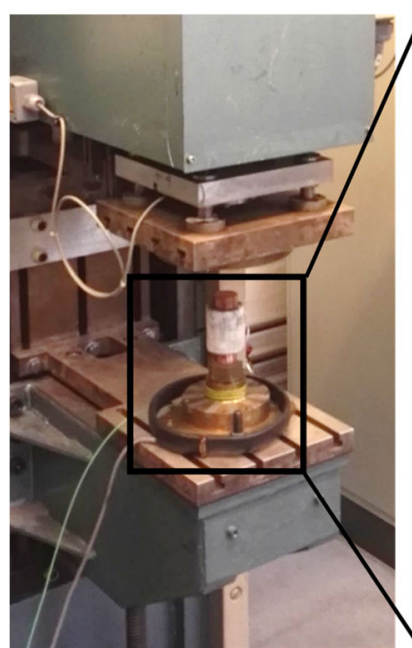

(a)

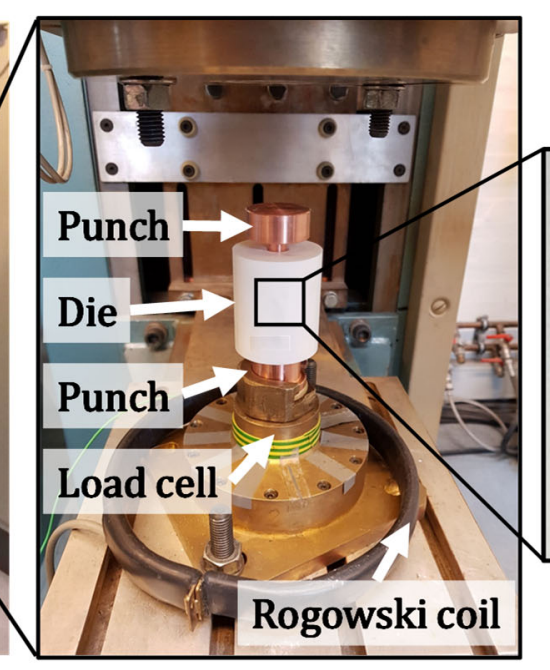

(b)

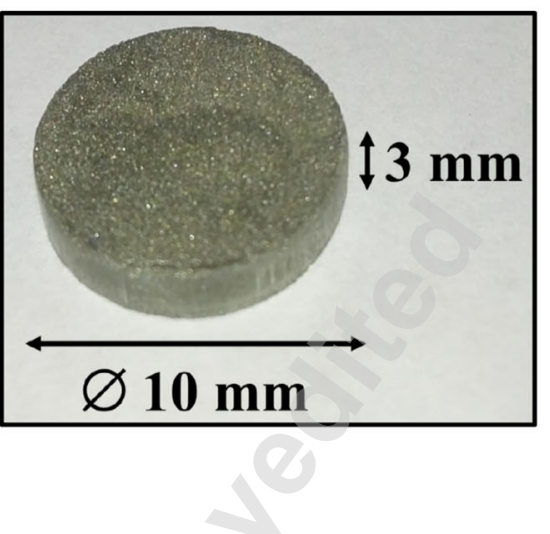

(c)

Figure 1. Resistance sintering experiments taking place in (a) a resistance welding machine with details of (b) the setup consisting of a die, two conductive punches and load and current transducers. An example of a sintered titanium disc is shown in (c).

\subsection{Material properties}

Commercially pure titanium powder, ASTM grade 2 and purity 99.7\%, (producer: GoodFellow) was used, and basic properties of the titanium powder is presented in Table 1 based on [27-29]. The raw titanium powder is shown in Figure 2 by an SEM micrograph. The powder has a maximum particle size of $150 \mu \mathrm{m}$ declared by the producer.

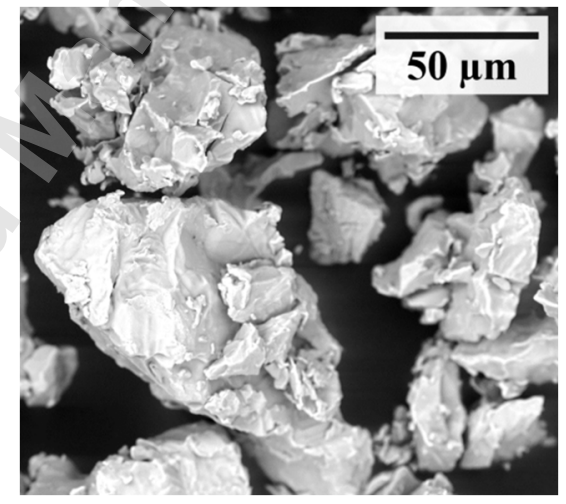

Figure 2. SEM micrograph of the raw titanium powder. 
Table. 1.Titanium powder properties [27-29].

\begin{tabular}{lrlc} 
Property & \multicolumn{2}{c}{ Value } & Symbol \\
\hline Thermal conductivity $\left(0-100^{\circ} \mathrm{C}\right)$ & 21.9 & $\mathrm{~W} /(\mathrm{m} \cdot \mathrm{K})$ & $\mathrm{k}$ \\
Specific heat capacity $\left(25^{\circ} \mathrm{C}\right)$ & 523 & $\mathrm{~J} /(\mathrm{kg} \cdot \mathrm{K})$ & $\mathrm{C}_{p}$ \\
Density $\left(20^{\circ} \mathrm{C}\right)$ & 4.51 & $\mathrm{~g} / \mathrm{cm}^{3}$ & $\rho_{m 0}$ \\
Electrical resistivity $\left(20^{\circ} \mathrm{C}\right)$ & 420 & $\mu \Omega \mathrm{mm}$ & $\rho_{0}$ \\
Temperature coefficient $\left(0-100^{\circ} \mathrm{C}\right)$ & 0.0035 & $1 / \mathrm{K}$ & $\alpha$
\end{tabular}

When it comes to simulation of resistance sintering, material data are needed as a function of both temperature and density. The electrical resistivity of the powder material during sintering is a central property for the process and hence for the simulation. Montes et al. [30-32] have theoretically described the electrical resistivity $\rho_{e}$ at room temperature as a function of the corresponding electrical resistivity at full density $\rho_{0}$ (i.e. corresponding to a bulk material) and the relative amount of porosity $\theta_{r}$ as,

$$
\rho_{e}=\rho_{0}\left(1-\theta_{r}\right)^{-e}
$$

where $e$ is a resistivity exponent expressed as,

$$
e=1+\left(1-\theta_{m}\right)^{\frac{4}{5}}
$$

based on the tap porosity $\theta_{m}$, which is the porosity after the powder has been vibrated inside the die before pre-compaction and sintering.

The effect of temperature is taken into account by Weiner et al. [33] by expressing the electrical resistivity $\rho_{t}$ through,

$$
\rho_{t}=\rho_{e}\left[1+\alpha\left(T-T_{0}\right)\right]
$$

where $\rho_{e}$ is taken from (1), $\alpha$ is the temperature coefficient of resistance, and $T$ and $T_{0}$ are the instantaneous and ambient temperatures, respectively.

Applying these equations with material data from Table 1 and assuming $T_{0}=20^{\circ} \mathrm{C}$, the variation of electrical resistivity with density and temperature is shown in Figure 3. The tap porosity of titanium powder was mathematically estimated as $\theta_{m}=0.5$ following the method presented in [30-32]. 


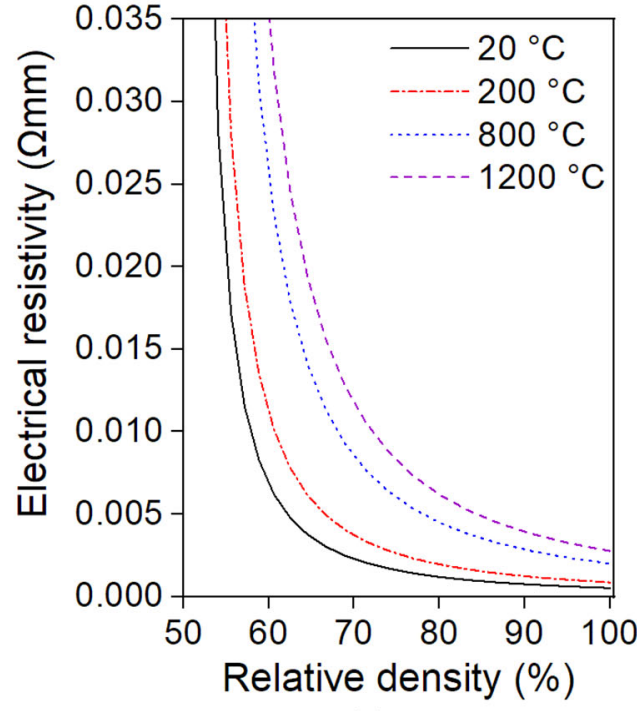

(a)

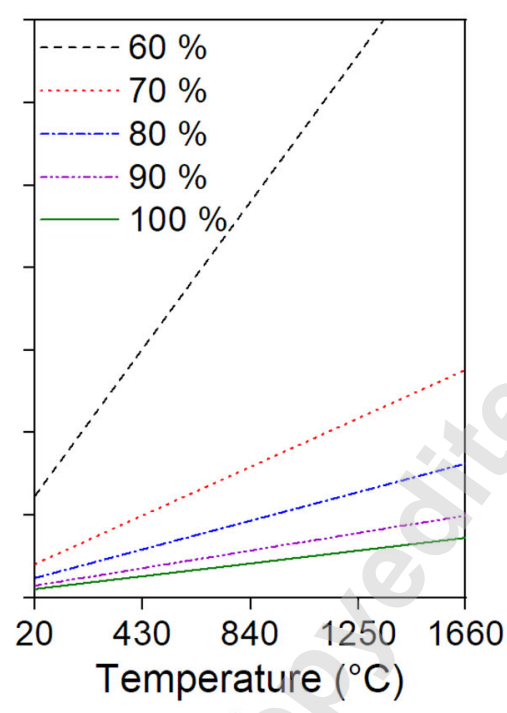

(b)

Figure 3. Variation of electrical resistivity as a function of (a) relative density at different levels of temperature and (b) temperature at different levels of relative density.

Heat is generated by the Joule effect as a function of the electrical resistivity and the current density. The corresponding temperature change is then governed by the specific heat capacity, which is shown as a function of temperature according to [29] in Figure 4.

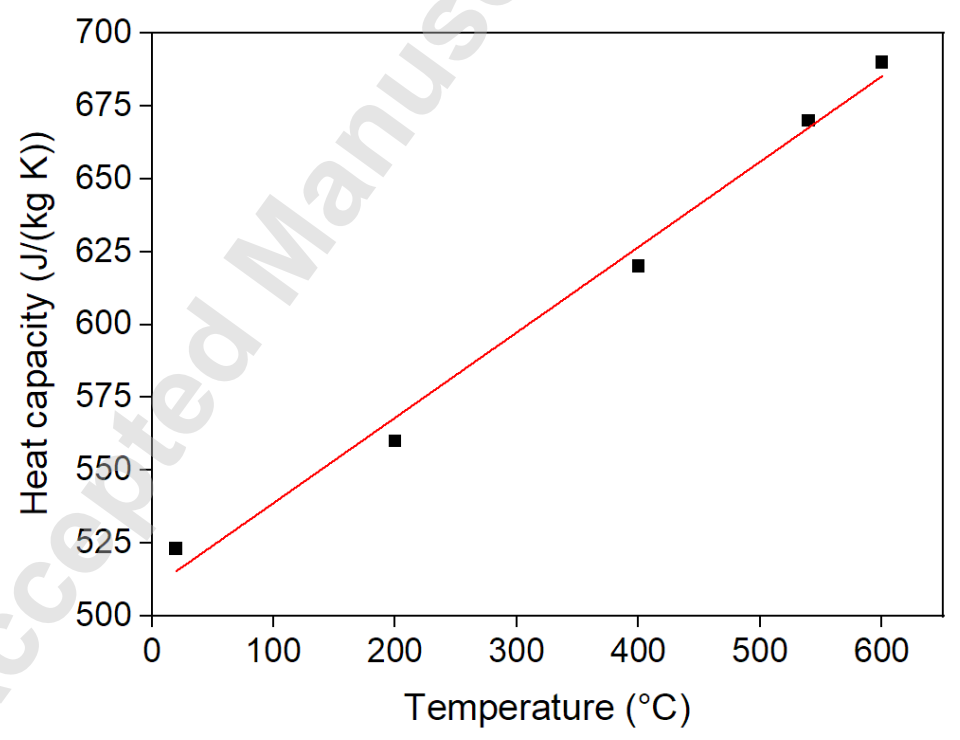

Figure 4. Specific heat capacity of titanium as a function of temperature [29].

The mechanical response of the material is expressed through flow stress curves at different levels of temperature. The influence of the relative density is included via the 
porous plasticity model to be presented in Section 3 in relation to the numerical model. Figure 5 includes flow stress curves (flow stress $\sigma_{f}$ as a function of equivalent strain $\varepsilon_{e q}$ ) of fully dense titanium at different temperatures. These curves are mathematically described by Hollomon equations (i.e. of the form $\sigma_{f}=C \varepsilon_{e q}^{n}$ ), where the strength coefficient $C$ and strain hardening exponent $n$ are fitted to stress and strain values at initial yield and break at different temperatures from literature [29].

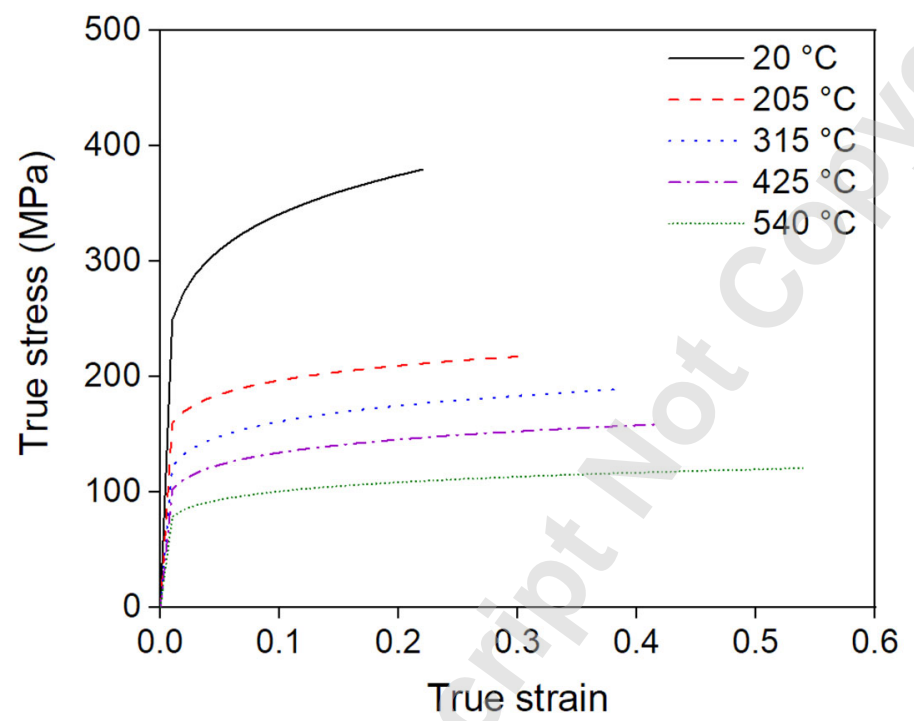

Figure 5. Flow stress of titanium in a true stress-strain diagram as a function of temperature. The flow stress refers to fully dense titanium.

\section{Numerical model}

The numerical model is based on the axisymmetric initial mesh in Figure 6, where bilinear quadrilateral elements discretize the cross-section by 800 elements in the disc being sintered and 400 elements in each electrode/punch. The die is assumed as rigid and both electrically and thermally non-conductive. Friction along the die is also neglected. Perfect thermal contact between the electrodes and the powder material is assumed.

The powder material undergoes large deformations, and a rigid-plastic model including porosities is used to simulate the deformation. Electrical and thermal models are employed to simulate the current density distribution, heat generation due to the Joule effect, and heat conduction to also predict temperature distributions. Each model is outlined by their governing equations in the following subsections. 


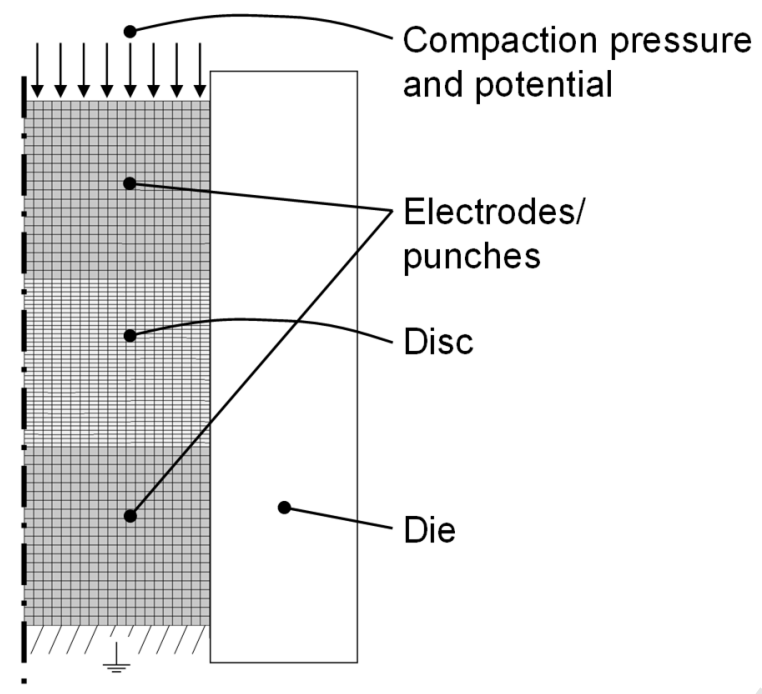

Figure 6. Initial mesh for simulation of resistance sintering of a disc between two electrodes/punches in a rigid die.

\subsection{Porous plasticity model}

Porous plasticity is here simulated by using the flow formulation (see [25] for more details) with the plastic response as a function of relative density described by the Shima and Oyane constitutive equations[34]. This is implemented by minimization of the following energy rate,

$$
\Pi=\int_{V} \bar{\sigma}_{r} \dot{\bar{\varepsilon}}_{r} d V+\int_{S_{t}} t_{i} u_{i} d S
$$

where the first term is due to plastic deformation of the powder material in the volume $V$ , and the second term is due to surface tractions on the surface $S_{t}$. Additional terms due to contact and friction can be included, but are not necessary here. The effective stress and effective strain rate at a relative density $r=1-\theta_{r}$ are denoted $\bar{\sigma}_{r}$ and $\dot{\bar{\varepsilon}}_{r}$, respectively. Surface tractions are denoted $t_{i}$ and velocities are denoted $u_{i}$.

While fully dense metals are incompressible, the powder material is compressible and the first invariant $I_{1}$ of the stress must be considered together with the second invariant $J_{2}^{\prime}$ of the deviatoric stress that is typical for the plasticity of metals. If the flow stress in fully dense conditions is denoted $\sigma_{f}$, the yield function becomes

$$
A J_{2}^{\prime}+B I_{1}^{2}=C \sigma_{f}^{2}=\bar{\sigma}_{r}^{2}
$$

where constants $A, B$ and $C$ are to be determined experimentally. In the special case of a fully dense material, they are $A=3, B=0$ and $C=1$, and (5) reduces to von Mises 
yield criterion. Otherwise, these constants are functions of the relative density $r$, and in case of the model by Shima and Oyane [34], they are,

$$
\begin{gathered}
A=\frac{3}{1+\frac{1}{9 \zeta^{2}}} \\
B=1-\frac{A}{3} \\
C=\frac{r^{5}}{1+\frac{1}{9 \zeta^{2}}}
\end{gathered}
$$

where $r$ is the relative density and $\zeta$ is expressed as a function of relative density as follows,

$$
\zeta=\frac{1}{2.49(1-r)^{0.514}}
$$

When considering the material to be a continuum with the apparent flow stress equal to the equivalent stress $\bar{\sigma}_{r}$ in equation (5) as a function of the relative density, the constitutive equations can be written as [35],

$$
d \varepsilon_{i j}=\frac{\dot{\bar{\varepsilon}}_{r}}{\bar{\sigma}_{r}}\left(\frac{A}{2} \sigma_{i j}^{\prime}+(3-A) \sigma_{m} \delta_{i j}\right)
$$

where $\sigma_{i j}^{\prime}$ is the deviatoric stress, $\sigma_{m}$ is the hydrostatic stress, $\delta_{i j}$ is the Kronecker delta, and the apparent effective strain rate is given by,

$$
\dot{\bar{\varepsilon}}_{r}=\left(\frac{2}{A} \varepsilon_{i j}^{2}+\frac{1}{3(3-A)} \dot{\varepsilon}_{v}{ }^{2}\right)^{1 / 2}
$$

with the volumetric strain rate being $\dot{\varepsilon}_{V}=-\frac{\dot{r}}{r}$. Further details of the porous plasticity model are given in $[35,36]$.

\subsection{Electrical model}

The current is applied through a difference in potential between the upper surface of the upper electrode and the lower surface of the lower electrode. The electrical potential $\Phi$ is then governed by

$$
\int_{V} \nabla \Phi \nabla(\delta \Phi) d V=0
$$

with $\nabla$ representing the vector differential operator with respect to space and $\delta$ indicates an arbitrary variation. This equation ignores transient effects which is reasonable for electrical effects when compared to the thermal effects. Having solved the potential field, 
the current density is given at any point as $j=\nabla \Phi / \rho_{t}$, where $\rho_{t}$ is the electrical resistivity in equation (3) considering both relative density and temperature.

Heating by the Joule effect is expressed as

$$
\dot{q}=\rho_{t} j^{2}
$$

where $\dot{q}$ is the heating rate per unit of volume.

\subsection{Thermal model}

The temperature field $T$ is solved by means of the following integral transient form of the heat transfer equation,

$$
\int_{V} k \nabla T \nabla(\delta T) d V-\int_{S_{n}} k(\nabla T \cdot n) \delta T d S_{n}+\int_{V} \rho_{m} C_{p} \frac{d T}{d t} \delta T d V-\int_{V} \dot{q} \delta T d V=0
$$

with the thermal conductivity $k$, mass density $\rho_{m}$, specific heat capacity $C_{p}$, outward normal $n$ to surface $S_{n}$, and heat rate from Joule heating $\dot{q}$ given by equation (13). Additional terms could be added due to convection, radiation and heating due to plastic deformation, but these are omitted here.

\section{Results and discussion}

\subsection{Pre-compaction}

The first step of the resistance sintering process is the mechanical compaction of the powder before the electrical current is supplied. This pre-compaction is analyzed separately with resulting compaction load as a function of relative density. The loose titanium powder had a relative density of $32 \%$ before being compacted, and with a compaction load of $13.2 \mathrm{kN}$ (corresponding to a compaction pressure of $169 \mathrm{MPa}$ ) the experimental relative density became $66 \%$ in average. Between experiments, the relative density varied between $62 \%$ and $70 \%$. These values are represented in blue in Figure 7.

The simulations were carried out with only the mechanical model active and with an initial relative density of $32 \%$. The compaction stroke was calculated by simple mass conservation to end the simulation at a relative density of $66 \%$. Good agreement is observed between the simulated prediction (solid, black curve) and the experimental result (white circle with horizontal, blue error bar) at the end of pre-compaction, with a deviation of approximately 4\% (Figure 7). However, not only the simulation trend goes through the spanned experimental spread, as the analytical calculations with Shima and Oyane's model (dashed, red curve in Figure 7) closely match the numerical estimates. 
Errors derived from finite element modelling of pre-compaction may therefore be neglected.

The simulation revealed a plastic equivalent strain of 0.74 , which was used as an initial strain together with an initial relative density of $66 \%$ when simulating the resistance sintering involving the current flow.

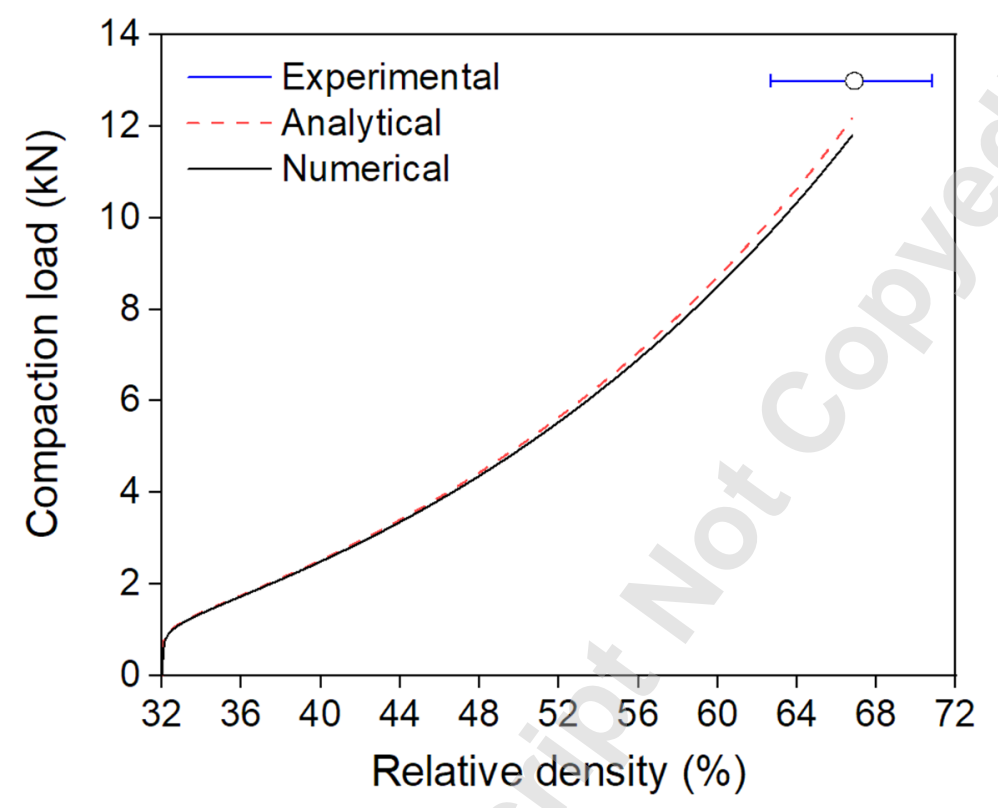

Figure 7. Compaction load as a function of relative density from analytical calculations and numerical simulations compared to the experimental point corresponding to the pre-compaction before applying the electrical current.

\subsection{Resistance sintering}

A number of sintering currents and sintering times were analyzed for each level of compaction pressure, and hence the pre-compaction was simulated once and supplying initial conditions for multiple sintering simulations with variations in current and time. Numerical results are compared to previously obtained experimental values [11]. Naturally, all the described numerical models were active during the simulation of resistance sintering with current flow and temperature changes.

Figure 8 shows the simulated and experimental values of relative density as a function of the electrical current density, while sintering time and compaction pressure were kept constant. The density varies over the sample after sintering due to cooling from the electrodes and the die, resulting in higher temperatures in the center of the sample. The density becomes high in the center and decreases towards the surfaces, which are more porous. The experimental relative density in Figure 8 is presented as an 
average value over the entire volume with error bars reflecting the process stability with small variations in the current density as a function of the total resistance and possible minor material loss of high porosity volumes at the surface during ejection of the sintered part. The simulated average relative density is also included for direct comparison with the experimental curve. A reasonable match exists between the two curves, although the simulated curve generally overestimates the density due to underestimation of the heat conduction to the die. Additionally, two curves from the simulation are included in the figure. These are the maximum and minimum relative densities, corresponding to the core and the surface respectively, to show the variation within the sample. These two curves of course span the curve of the average relative density. The average is based on a weighted volumetric calculation, and since the porous volume is smaller than the denser volume in the core, the average is closer to the maximum than to the minimum.

Figure 9 shows a similar set of curves for four different sintering times, while electrical current density and compaction pressure were kept constant. Besides a good match between simulated and experimental values, it is also noted how the sintering time influences the homogeneity of the sample. At the shortest sintering time, the difference between the minimum and maximum density is larger, while longer sintering times allow more homogeneous heating. 


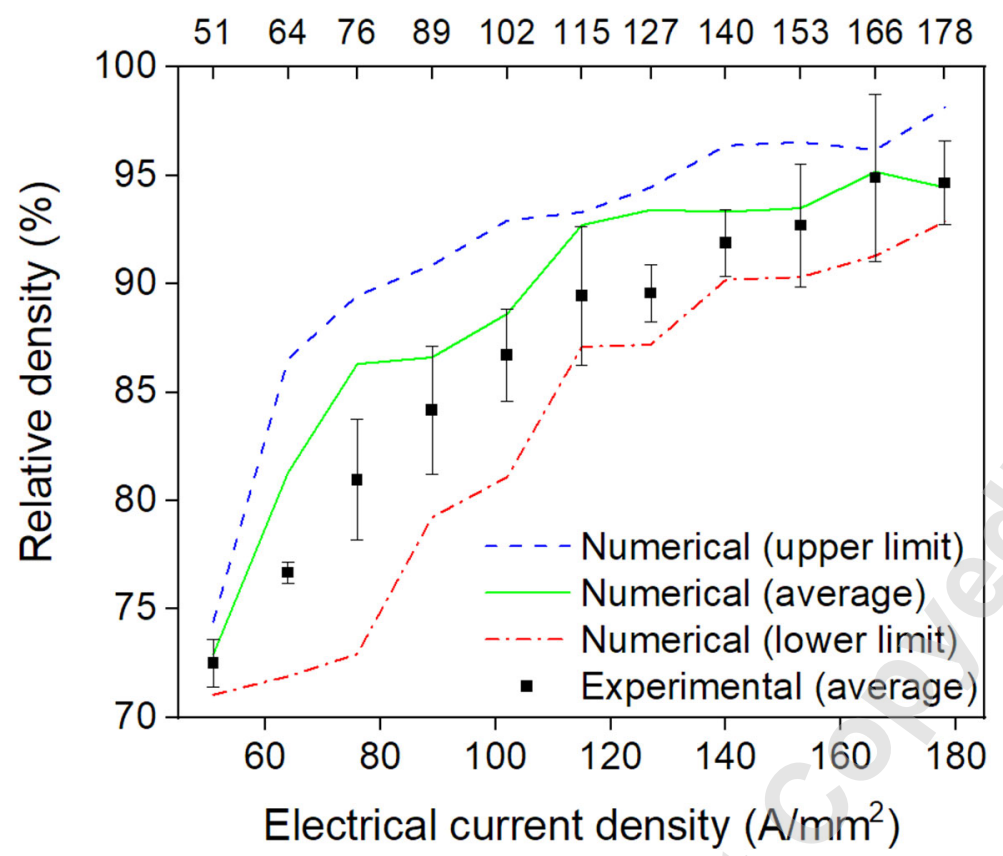

Figure 8. Relative density as a function of electrical current density in case of $150 \mathrm{~ms}$ sintering time and $169 \mathrm{MPa}$ compaction pressure. Experimental points represent five repetitions.

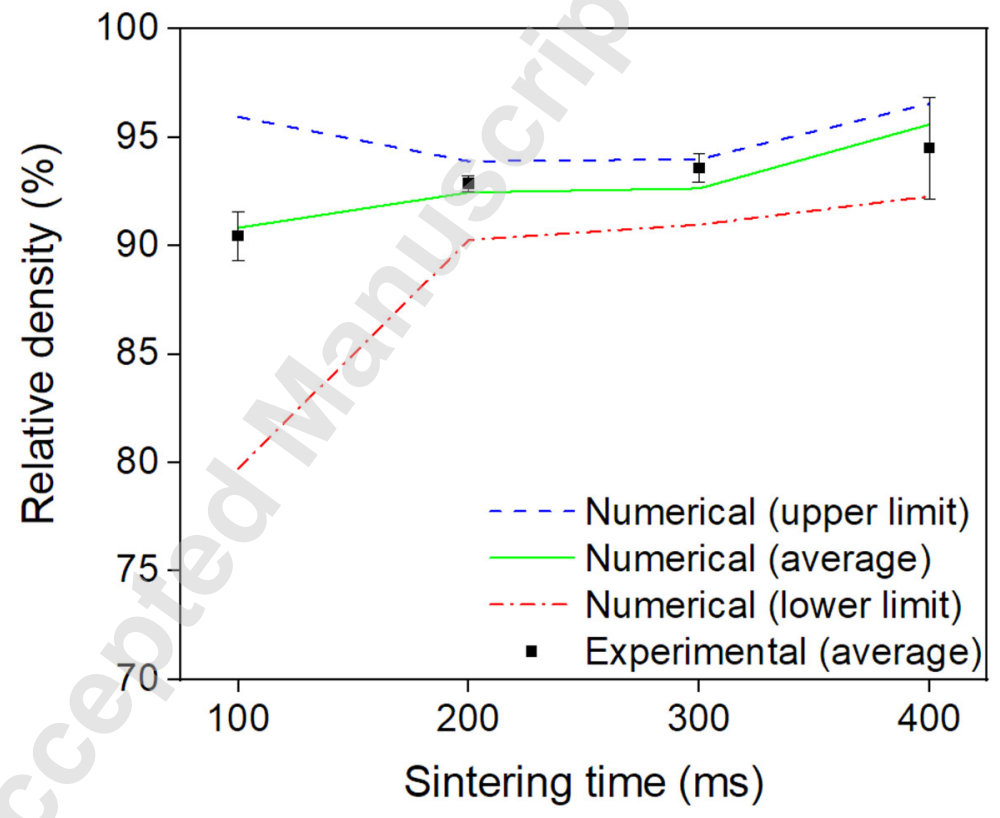

Figure 9. Relative density as a function of sintering time in case of electrical current density $115 \mathrm{~A} / \mathrm{mm}^{2}$ and $169 \mathrm{MPa}$ compaction pressure. Experimental points represent three repetitions.

The simulated temperatures in the core and the end surface are presented in Figure 10 as a function of the electrical current density for constant values of sintering time and 
compaction pressure. The melting temperature of titanium, $1660{ }^{\circ} \mathrm{C}$, is also included in the figure for reference. With these process settings, this means that melting in the core starts around an electrical current density of $140 \mathrm{~A} / \mathrm{mm}^{2}$, while $165 \mathrm{~A} / \mathrm{mm}^{2}$ would be necessary for melting the end face (refer to the dashed, blue, horizontal threshold line). Melting and rapidly solidified material in the core was seen in the experimental crosssections by the presence of dendrites.

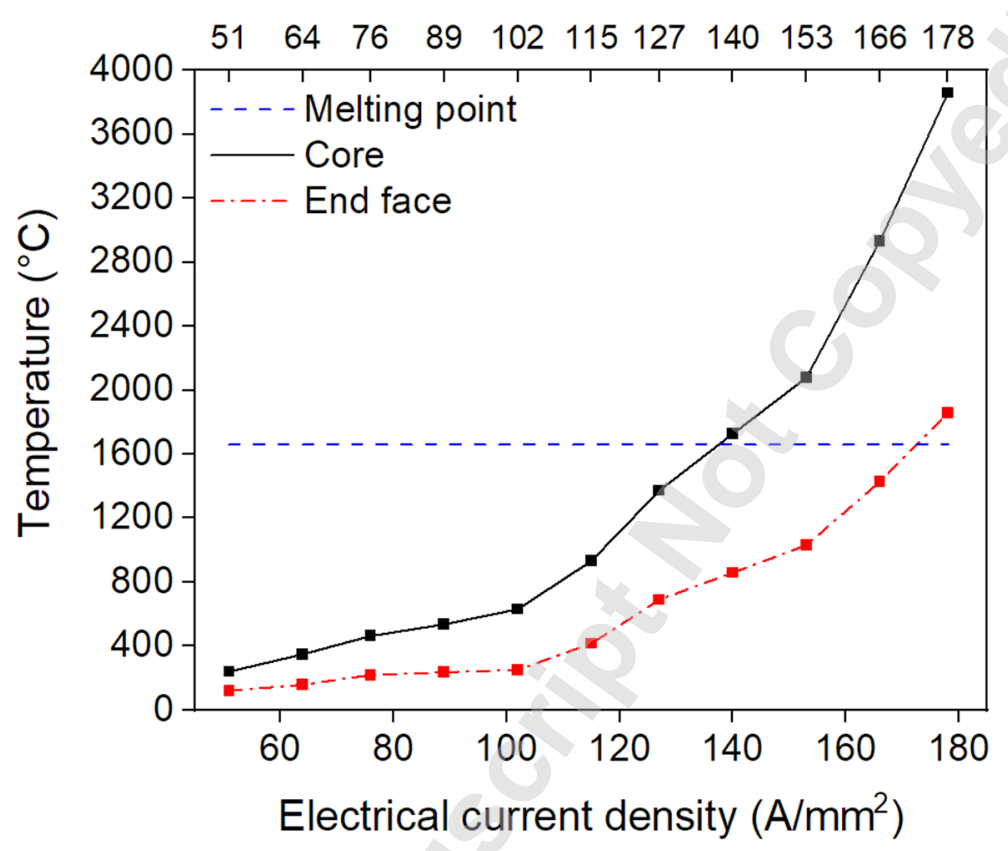

Figure 10. Temperature as a function of electrical current density in case of $150 \mathrm{~ms}$ sintering time and $169 \mathrm{MPa}$ compaction pressure.

Experimental cross-sections are shown in the left side of Figure 11 for three levels of electrical current density and constant sintering time and compaction pressure. The right side of Figure 11 includes the corresponding simulated process peak temperatures. The distribution of microstructure and the oval-shaped iso-lines of the temperature fields compare well, and it is again noticed how the maximum temperature is in the core and the minimum temperature is at the end faces as also noticed by $[2,14,37]$. This is a typical temperature distribution in resistance sintering, while for example spark plasma sintering would result in a more uniform temperature field by having the die heated $[16,19]$. 


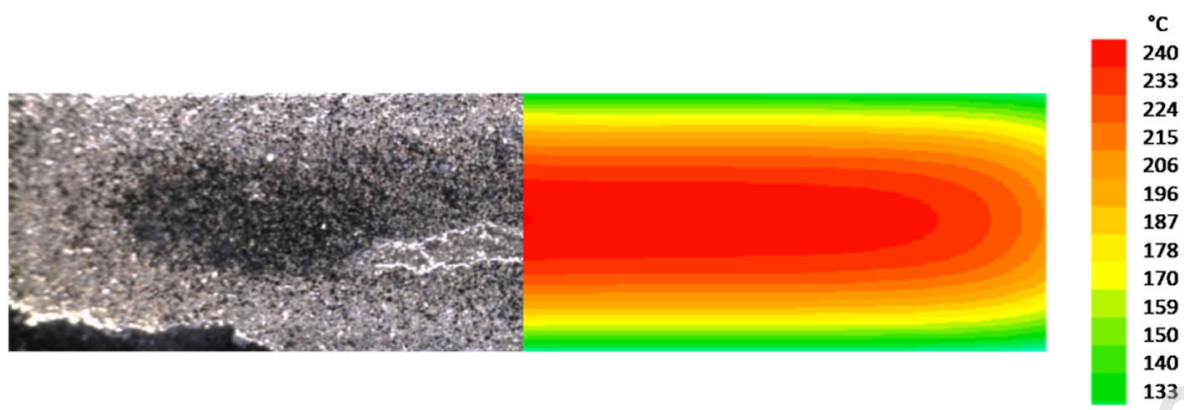

(a)

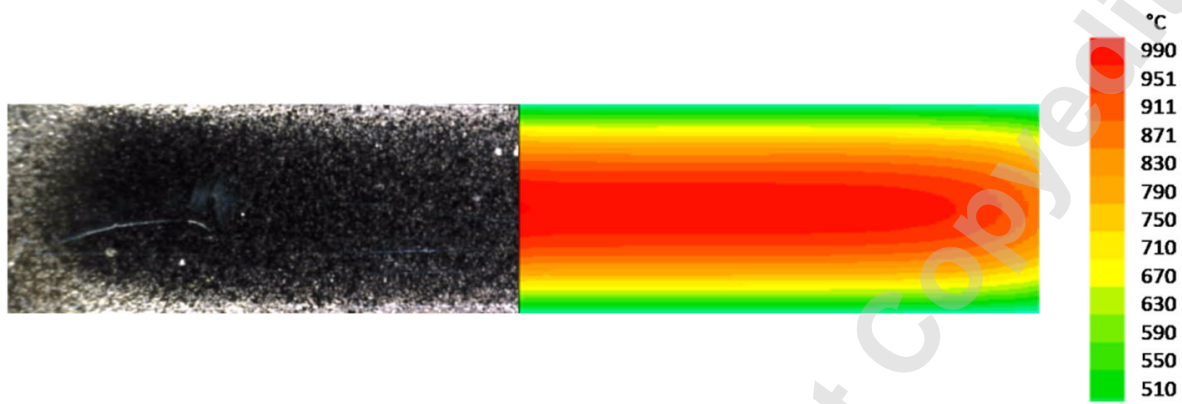

(b)

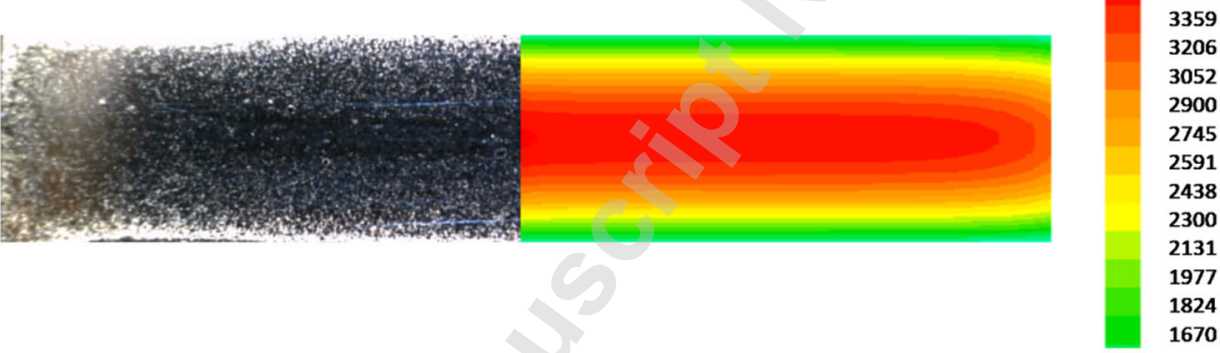

(c)

Figure 11. Combined experimental cross-sections and simulated temperature distributions in case of $150 \mathrm{~ms}$ sintering time and $169 \mathrm{MPa}$ compaction pressure. Three levels of electrical current density are included: (a) $51 \mathrm{~A} / \mathrm{mm}^{2}$, (b) $115 \mathrm{~A} / \mathrm{mm}^{2}$ and (c) $166 \mathrm{~A} / \mathrm{mm}^{2}$.

\section{Conclusions}

Numerical modeling of resistance sintering of titanium using the finite element method has been presented, and results were compared with experiments. The titanium powder was in all stages considered as a continuum, while the porosities were considered through a porous plasticity model by Shima and Oyane [34] that accounts for the changes in the distribution of relative density during the process. Heating by the Joule effect was taken into consideration by modelling the electrical field and by using electrical resistivity values that vary with both relative density and temperature. The conversion of heat into temperature increase and the development of the temperature 
field were also handled by finite elements in order to obtain a fully coupled electrothermo-mechanical model. The following conclusions can be drawn:

- Given the good agreement between simulated compaction load, relative density and temperature distributions and the experiments, it can be concluded that simulation based on a continuum model and a distribution of porosities is sufficient for accurate modeling of the overall response to changes in process parameters.

- The simulations presented here would be applicable to optimization of process parameters in terms of target relative density and its distribution, and in terms of the developed temperatures. For resistance sintering of other materials, such as permanent magnets, the temperature is important for the developed structures, because it influences the physical properties of the magnets [13].

- Finally, it is fair to conclude that simulation of resistance sintering is depending on a large amount of material data, which e.g. for magnetic materials are not easily available.

\section{Acknowledgements}

This research work was funded by MICROMAN project ("Process Fingerprint for Zerodefect Net-shape MICROMANufacturing", http:/www.microman.mek.dtu.dk. MICROMAN is a European Training Network supported by Horizon 2020, the EU Framework Programme for Research and Innovation Project ID: 674801). Paulo Martins would additionally like thank the support of Fundação para a Ciência e a Tecnologia of Portugal and IDMEC under LAETA-UIDB/50022/2020 and PTDC/EME-EME/0949/2020.

\section{References}

[1] Castro, R. H. R., 2013, "Overview of Conventional Sintering," Sintering, R.H.R. Castro, and K. van Benthem, eds., Springer, pp. 1-16.

[2] Olevsky, E. A., and Dudina, D. V., 2018, Resistance Sintering, Springer International Publishing, Cham.

[3] Lagos, M. A., Agote, I., Schubert, T., Weissgaerber, T., Gallardo, J. M., Montes, J. M., Prakash, L., Andreouli, C., Oikonomou, V., Lopez, D., and Calero, J. A., 2017, "Development of Electric Resistance Sintering Process for the Fabrication of Hard 
Metals: Processing, Microstructure and Mechanical Properties," Int. J. Refract. Met. Hard Mater., 66, pp. 88-94.

[4] Yang, Y. F., and Qian, M., 2015, Spark Plasma Sintering and Hot Pressing of Titanium and Titanium Alloys, Elsevier Inc.

[5] Cuevas, F. G., Andreouli, D., Gallardo, J. M., Oikonomou, V., Cintas, J., Torres, Y., and Montes, J. M., 2019, "Ceramic Dies Selection for Electrical Resistance Sintering of Metallic Materials," Ceram. Int., 45(12), pp. 14555-14561.

[6] Forno, I., Actis Grande, M., and Fais, A., 2015, "On the Application of ElectroSinter-Forging to the Sintering of High-Karatage Gold Powders," Gold Bull., 48(34), pp. 127-133.

[7] Fais, A., Leoni, M., and Scardi, P., 2012, "Fast Sintering of Nanocrystalline Copper," Metall. Mater. Trans. A, 43(5), pp. 1517-1521.

[8] Cuevas, F., Gallardo, J., Torres, Y., Astacio, R., Weissgaerber, T., Lagos, M., Montes, J., and Cintas, J., 2019, "Production of Ultrafine Grained Hardmetals by Electrical Resistance Sintering," Metals (Basel)., 9(2), p. 159.

[9] Lagos, M. A., Agote, I., Leizaola, I., Lopez, D., and Calero, J. A., 2020, "Fabrication of Chromium Carbide Cermets by Electric Resistance Sintering Process: Processing, Microstructure and Mechanical Properties," Int. J. Refract. Met. Hard Mater.

[10] Montes, J. M., Rodríguez, J. A., Cuevas, F. G., and Cintas, J., 2011, "Consolidation by Electrical Resistance Sintering of Ti Powder," J. Mater. Sci., 46(15), pp. 5197-5207.

[11] Cannella, E., Nielsen, C. V., and Bay, N., 2019, "Process Investigation and Mechanical Properties of Electro Sinter Forged (ESF) Titanium Discs," Int. J. Adv. Manuf. Technol., 104(5-8), pp. 1985-1998.

[12] Leich, L., Röttger, A., Theisen, W., and Krengel, M., 2018, "Densification of Nanocrystalline NdFeB Magnets Processed by Electro-Discharge Sintering Microstructure, Magnetic, and Mechanical Properties," J. Magn. Magn. Mater., 460, pp. 454-460.

[13] Cannella, E., Nielsen, C. V., and Bay, N., 2020, "Resistance Sintering of NdFeBCo Permanent Magnets and Analysis of Their Properties," CIRP J. Manuf. Sci. Technol., 29, pp. 88-98.

[14] Di Napoli, P., Cagliero, R., and Maizza, G., 2015, "Micro-Macro Analysis of Capacitor Discharge Sintering in Copper-Diamond Bead," J. Am. Ceram. Soc., 
98(11), pp. 3538-3546.

[15] Maizza, G., and Tassinari, A., 2009, "Modelling of Micro/Macro Densification Phenomena of Cu Powder during Capacitor Discharge Sintering," COMSOL Conference 2009.

[16] McWilliams, B., Zavaliangos, A., Cho, K. C., and Dowding, R. J., 2006, "The Modeling of Electric-Current-Assisted Sintering to Produce Bulk Nanocrystalline Tungsten," Jom, 58(4), pp. 67-71.

[17] Zhang, Y., Wu, L., Guo, X., Jung, Y. G., and Zhang, J., 2016, "Molecular Dynamics Simulation of Electrical Resistivity in Sintering Process of Nanoparticle Silver Inks," Comput. Mater. Sci.

[18] Wei, X., Giuntini, D., Maximenko, A. L., Haines, C. D., and Olevsky, E. A., 2015, "Experimental Investigation of Electric Contact Resistance in Spark Plasma Sintering Tooling Setup," J. Am. Ceram. Soc., 98(11), pp. 3553-3560.

[19] Tiwari, D., Basu, B., and Biswas, K., 2009, "Simulation of Thermal and Electric Field Evolution during Spark Plasma Sintering," Ceram. Int., 35(2), pp. 699-708.

[20] Braginsky, M., Tikare, V., and Olevsky, E., 2005, "Numerical Simulation of Solid State Sintering," International Journal of Solids and Structures.

[21] Garcia, C., and Olevsky, E., 2010, "Numerical Simulation of Spark Plasma Sintering," Adv. Sci. Technol., 63, pp. 58-61.

[22] Allen, J. B., and Walter, C., 2012, "Numerical Simulation of the Temperature and Stress Field Evolution Applied to the Field Assisted Sintering Technique," ISRN Mater. Sci., 2012, pp. 1-9.

[23] Nielsen, C. V., Zhang, W., Perret, W., Martins, P. A. F., and Bay, N., 2015, "Three-Dimensional Simulations of Resistance Spot Welding," Proc. Inst. Mech. Eng. Part D J. Automob. Eng.

[24] Nielsen, C. V., Zhang, W., Martins, P. A. F., and Bay, N., 2015, "3D Numerical Simulation of Projection Welding of Square Nuts to Sheets," J. Mater. Process. Technol.

[25] Nielsen, C. V., Zhang, W., Alves, L. M., Bay, N., and Martins, P. A. F., 2013, "Coupled Finite Element Flow Formulation," Modelling of Thermo-ElectroMechanical Manufacturing Processes with Applications in Metal Forming and Resistance Welding, Springer-Verlag, London, UK, pp. 11-36.

[26] Cannella, E., Nielsen, C. V., and Bay, N., 2019, "On the Process and Product Fingerprints for Electro Sinter Forging (ESF)," Micromachines, 10(4). 
[27] GoodFellow, 2017, "Titanium Powder (Ti)-Material Information" [Online]. Available: http://www.goodfellow.com/E/Titanium-Powder.html. [Accessed: 20Mar-2017].

[28] Ness Engineering, "Technical Data” [Online]. Available: http://www.nessengr.com/techdata/metalresis.html. [Accessed: 22-Oct-2020].

[29] MatWeb, 2017, "Material Property Data - Titanium Grade 2" [Online]. Available: http://www.matweb.com/search/datasheet.aspx?MatGUID=24293fd5831941ec9fa 01dce994973c7. [Accessed: 22-Oct-2017].

[30] Montes, J. M., Cuevas, F. G., and Cintas, J., 2007, "Electrical Resistivity of Metal Powder Aggregates," Metall. Mater. Trans. B Process Metall. Mater. Process. Sci., 38(6), pp. 957-964.

[31] Montes, J., Cuevas, F., Ternero, F., Astacio, R., Caballero, E., and Cintas, J., 2017, "A Method to Determine the Electrical Resistance of a Metallic Powder Mass under Compression," Metals (Basel)., 7(12), p. 479.

[32] Montes, J. M., Cuevas, F. G., and Cintas, J., 2011, "Electrical Resistivity of a Titanium Powder Mass," Granul. Matter, 13(4), pp. 439-446.

[33] Weiner, L., Chiotti, P., and Wilhelm, H. A., 1952, "Temperature Dependence of Electrical Resistivity of Metals," Ames Lab. ISC Tech. Reports Ames Lab., 12.

[34] Shima, S., and Oyane, M., 1976, "Plasticity Theory for Porous Metals," Int. J. Mech. Sci., 18(6), pp. 285-291.

[35] Marques, M. J. M. B., and Martins, P. A. F., 1991, "A General Three-Dimensional Finite Element Approach for Porous and Dense Metal-Forming Processes," Proc. Inst. Mech. Eng. Part B J. Eng. Manuf., 205(4), pp. 257-263.

[36] Alves, L. M. M., Martins, P. A. F., and Rodrigues, J. M. C., 2006, "A New Yield Function for Porous Materials," J. Mater. Process. Technol., 179(1-3), pp. 36-43.

[37] Montes, J. M., Cuevas, F. G., Cintas, J., and Urban, P., 2014, "A OneDimensional Model of the Electrical Resistance Sintering Process," Metall. Mater. Trans. A, 46(2), pp. 963-980. 